\title{
8
}

\section{A Suite of Tools for Efficient Modeling of Complex Collection Systems using SWMM}

\author{
Khalid N. Khan, Sangameswaran Shyamprasad, Gary Mercer and \\ James T. Smullen
}

The U.S. Environmental Protection Agency's Storm Water Management Model (SWMM) model uses a non-linear reservoir algorithm to compute runoff by dynamically routing flows while taking into account the backwater and pressurized flow conditions. These abilities of SWMM enable detailed modeling of complex urban collection systems. Advancement in the computer memory and processing speed has encouraged development of complex collection system models. As complexity increases, detailed representation of the system is often limited by the ability of the available tools in SWMM to prepare large input datasets for the model simulation as well as to perform adequate quality assurance checks on the model simulation results. Moreover, some of the unique methodologies utilized in such complex models cannot be handled by the inbuilt functionalities of some readily available third party software which are designed to address the more general applications of the models. Experience with modeling large urban collection systems suggests that the one-size-fits-all concept does not always work. This chapter presents a discussion of some of the customized tools developed to assist with the hydrologic and hydraulic $(\mathrm{H} \& \mathrm{H})$ modeling of complex urban service area for the Allegheny County Sanitary Authority (ALCOSAN) in south-western Pennsylvania using SWMM5.

The customized tools presented in this chapter include those developed to prepare the model, the input datasets and the post-processing of the model

Khan, K., S. Shyamprasad, G. Mercer and J. Smullen. 2010. "A Suite of Tools for Efficient Modeling of Complex Collection Systems using SWMM." Journal of Water Management Modeling R236-08. doi: 10.14796/JWMM.R236-08.

(C) CHI 2010 www.chijournal.org ISSN: 2292-6062 (Formerly in Dynamic Modeling of Urban Water Systems. ISBN: 978-0-9808853-3-0) 
simulation results. The tools or programs were developed using the Statistical Analysis Software (SAS). Programs were developed to process the GIS information to create slope categories for the sub-catchments, process the calibrated radar rainfall data to develop area-weighted precipitation time series for each sewershed and process the quality assured flow monitoring data to develop the dry weather flow hydrographs at all point of connections to the collection system for direct input into the model. Post-processing programs were developed to facilitate the hydrologic validation of the monitored sewersheds, to generate various types of plots to assist with the quality assurance checks of the model simulation results and to generate overflow discharge summary reports for all outfalls in the system to quantify the combined sewer overflow (CSO) and separate sewer overflow (SSO) discharges into the receiving waters.

\subsection{Background}

\subsubsection{Overview of ALCOSAN}

ALCOSAN provides conveyance and treatment for sanitary and wet weather flow to the city of Pittsburgh and all or part of 82 regional municipalities. The service area spans approximately $300 \mathrm{mi}^{2}\left(780 \mathrm{~km}^{2}\right)$ with a service population of 939000 people based on the 2000 census. The conveyance system comprises approximately $90 \mathrm{mi}(144 \mathrm{~km})$ interceptor sewer, which includes approximately $30 \mathrm{mi}(48 \mathrm{~km})$ deep tunnel interceptors, at a depth of $20 \mathrm{ft}$ to $175 \mathrm{ft}(6 \mathrm{~m}$ to $53 \mathrm{~m}$ ) below ground, primarily in the $80 \mathrm{ft}$ to $100 \mathrm{ft}$ ( $24 \mathrm{~m}$ to $30 \mathrm{~m}$ ) range, and approximately $60 \mathrm{mi}(96 \mathrm{~km})$ shallow-cut interceptors. The present secondary treatment capacity of the wastewater treatment plant is approximately $250 \mathrm{mgd}$ $(945 \mathrm{ML} / \mathrm{d})$. About 300 regulator structures along the interceptor sewers intercept the dry weather flow and control the wet weather flow into the ALCOSAN conveyance system. ALCOSAN does not have jurisdiction over the local collection systems, which are owned and operated by the regional municipalities (Khan and Meeneghan, 2006).

In order to control the frequency and amount of CSO and SSO discharges into the regional water bodies, ALCOSAN is in the process of developing and implementing a regional wet weather plan. The regional water bodies receiving ALCOSAN discharges are the three main rivers, Allegheny, Monongahela and Ohio, and four tributaries, Chartier's Creek, Saw Mill Run, Thompson Run and Turtle Creek. In order to develop and evaluate alternative conveyance and control facilities to regulate the frequency and volume of CSO and SSO discharges, ALCOSAN has developed detailed H\&H computer simulation models. The 
point of connection system wide model consists of approximately 2850 nodes, 2650 conduits and 360 outfalls. The size of the model is expected to increase significantly after the inclusion of the municipal collection system details.

\subsubsection{Need for Customized Programs}

SWMM5 provides a dependable GUI which performs efficiently, developing statistics and viewing of results when the size of the models and the model simulation output files is small. As the models and input datasets become large, so do the generated output files. To efficiently create and manage these large input datasets and analyze the output files customized pre- and post-processing programs are needed.

To assist with the model refinement process, prepare input datasets and analyze the output files for the ALCOSAN H\&H models, application programs were developed using SAS which is very adept at processing large time series datasets. The application programs can broadly be divided into two categories:

- Pre-processing programs which include programs:

1. To perform slope analysis for sub-catchments;

2. Develop sewershed precipitation;

3. Develop dry weather flow hydrographs;

- Post-processing programs which include programs:

1. To generate hydrologic validation plots;

2. To generate plots for quality assurance of model simulation results; and

3. To generate overflow discharge statistics and plots.

\subsection{Pre-Processing Programs}

\subsubsection{Slope Analysis for Sub-Catchments}

Slope of a sewershed is a very important hydrologic parameter when estimating surface runoff rate and volume. It becomes especially important when the topography of the area being modeled is very undulating with ample variation in the ground surface slope, and when the area being modeled is large.

Furthermore impervious and pervious areas respond differently to precipitation. Since SWMM allows for only one slope value for a modeled sewershed, the use of a mean slope for a large area which may consist of both impervious and pervious areas might not produce very representative system responses. It 
is for this reason that area for each sewershed can be divided into two portions that is impervious and pervious which then can be further divided into 4 slope categories each to result in 8 small sub-catchments to represent one sewershed. This process is performed for each sewershed area as they are approached for future hydrologic modeling.

Slope categories can be tailored to each sewershed region and can be assigned according to the distribution of slopes throughout that sewershed area. These slope categories include four sub-catchments for both the impervious and pervious areas designed to give a fast, medium, slow and very slow runoff rate. The application program essentially helps develop areas and their mean weighted slope for these 8 sub-catchments.

In SWMM, the slope of overland flow is a non-linear parameter when estimating runoff from the combined sewer areas.

$$
Q=\frac{1.486}{n} \times W \times\left(d-d_{s}\right)^{5 / 3} \times s^{1 / 2}
$$

where:

$$
\begin{aligned}
Q= & \text { surface runoff }\left(\mathrm{ft}^{3} / \mathrm{s}\right) \\
W= & \text { width of watershed }(\mathrm{ft}) \\
s= & \text { average slope of watershed }(\mathrm{ft} / \mathrm{ft}) \\
d= & \text { depth in the non-linear reservoir }(\mathrm{ft}) \\
n= & \text { Manning's roughness coefficient, and } \\
d_{s}= & \text { depression storage depth in the non-linear reservoir } \\
& (\mathrm{ft}) .
\end{aligned}
$$

The rate of runoff from the non-linear reservoir is governed by the Manning's roughness coefficient, the width of the watershed and the average slope of the watershed. Unlike the roughness coefficient and the width of the watershed, slope is a quantifiable physical parameter and therefore is not adjusted during the validation process.

One of the common difficulties encountered when validating the runoff from a combined sewer area is under-simulating the extended recession limbs of the hydrograph. Because the slope is a non-linear parameter in Manning's equation, estimating an average ground slope for the sewershed may neglect extended runoff periods produced in the very low sloped areas of the sewershed. The effect of slopes on the runoff recession limb is demonstrated in Figure 8.1. The demonstration assumes a non-linear reservoir of 1 in. (25.4 $\mathrm{mm}$ ) subject to Manning's equation with a $400 \mathrm{ft}$ (121.92 m) overland flow width and a roughness coefficient of 0.30 . Calculations were performed using a $15 \mathrm{~s}$ time step. 


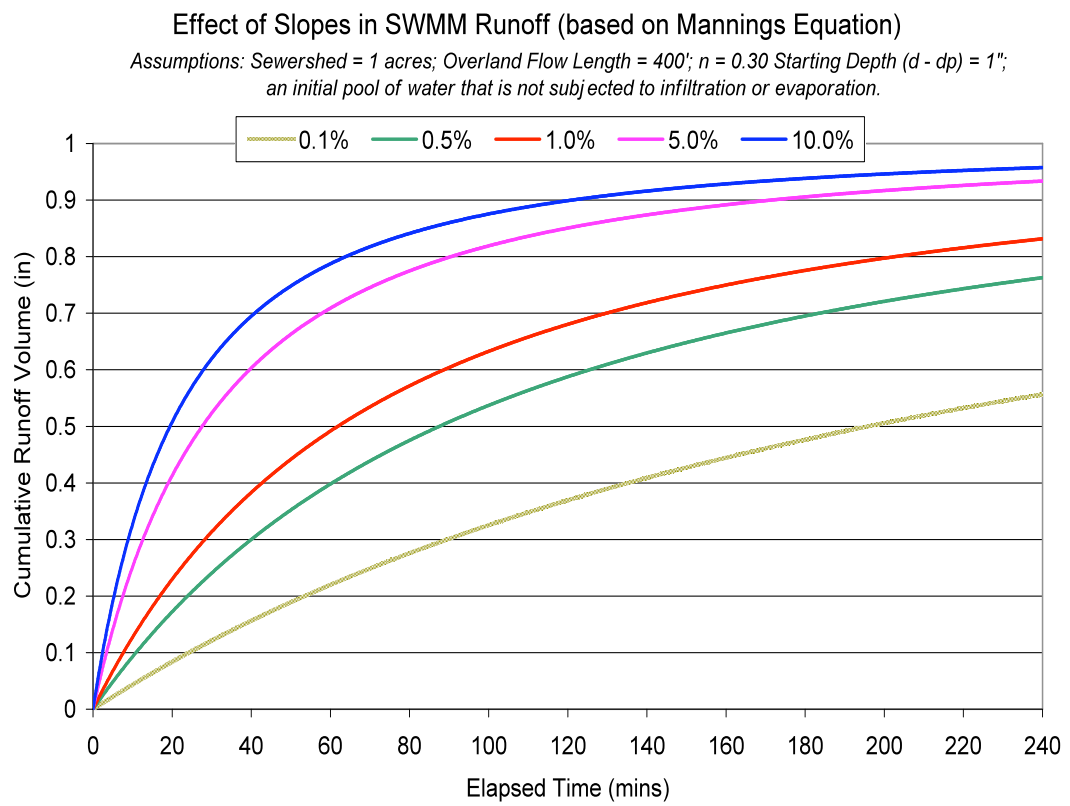

Figure 8.1 Effect of slope on runoff hydrograph recession limb.

The attenuation of runoff becomes progressively larger as the slopes are reduced. In addition, that attenuation becomes more sensitive to slope as the slopes are reduced.

The GIS is used to calculate the slopes for the combined sewersheds. The process begins using $5 \mathrm{ft}$ contours. These contours are converted to a triangulated irregular network (TIN) using tools in the GIS. The TIN provides a continuous vector based representation of ground surface elevation interpolated between the contour lines. This TIN is then converted to a slope grid comprised of $20 \mathrm{ft} \times 20 \mathrm{ft}$ ( $6.096 \mathrm{~m} \times 6.096 \mathrm{~m})$ pixels. Each pixel contains one slope value that is calculated using the weighted average of the TIN elements, which it intersects. This slope grid is finally intersected with the sewersheds and a table is generated for each unique slope grid value within each sewershed, with a further distinction made between impervious and pervious areas.

The shdfrq.txt file is the total area $\left(\mathrm{ft}^{2}\right)$ of each sewershed for which the slope categories need to be developed. Figure 8.2 shows a screen shot of an example shdfrq.txt file. Each sewershed is assigned a unique grid-id. 


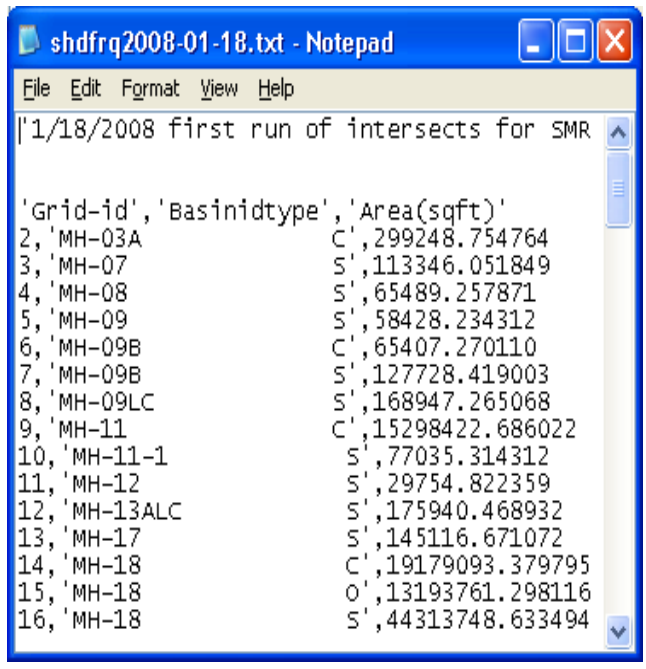

Figure 8.2 Example sewershed area shdfrq.txt file.

The shdout.txt file is the result of intersecting the $20 \mathrm{ft} \times 20 \mathrm{ft}(6.096 \mathrm{~m} \mathrm{x}$ $6.096 \mathrm{~m}$ ) slope layer with the impervious layer and the sheds layer. Figure 8.3 shows a screen shot of an example shdout.txt file. The Value column is a unique identifier. The table gives the total acre area of the cells. The Count column is the number of $20 \mathrm{ft} \times 20 \mathrm{ft}(6.096 \mathrm{~m} \times 6.096 \mathrm{~m})$ cells at the slope value. The Slope*100 column is the percentage slope multiplied by 100 . The ImpgridID column is a four digit value comprised of the unique basin ID value with a prefix that designates imperviousness of the area. Impervious values begin with a 1 while pervious values begin with a 2 . The Acres column is the total area in acres of the cells after the GIS intersect. The Slope column is the percent slope calculated for the area.

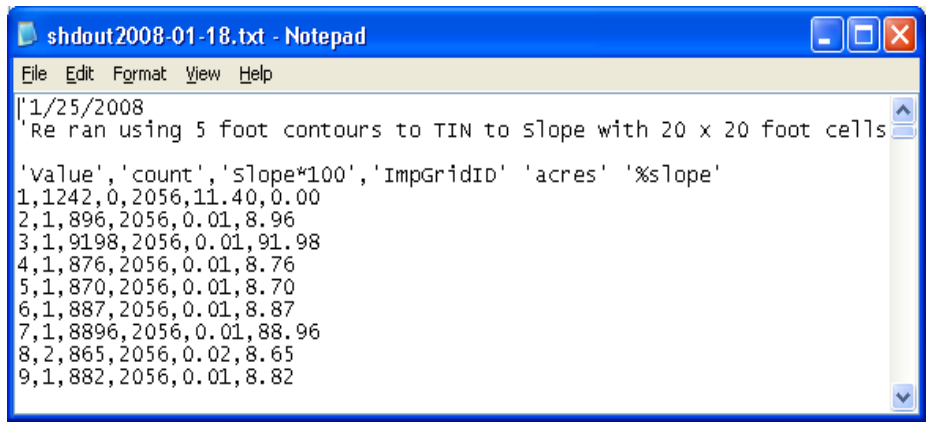

Figure 8.3 Example impervious and shed layer intersect shdout.txt file. 
SAS uses these files to build a table of the total impervious and pervious acres for each sewershed based on the desired slope categories. The sewersheds are linked by the unique Grid-id in the shdfrq.txt table and the ImpgridID in the shdout.txt table. The value of the Grid-id variable is the ImpgridID minus the impervious or pervious prefix. The desired slope categories are user defined in the SAS program. The result is a table shown in Table 8.1.

Table 8.1 Slope analysis result summary.

\begin{tabular}{|c|c|c|c|c|c|c|c|c|}
\hline MinSlope & MaxSlope & Category & CatNum & ImpID & ImpY N & BasinType & acres & perslope \\
\hline$\overline{0}$ & $\overline{0.3}$ & zero & $\overline{4}$ & $\overline{1}$ & $\bar{Y}$ & "MH_03A_C_ & 0.93 & $\overline{0}$ \\
\hline 0 & 0.3 & zero & 4 & 1 & $Y$ & $\mathrm{MH}^{-09 B} \mathrm{C}^{-}$ & 0.17 & 0 \\
\hline 0 & 0.3 & zero & 4 & 1 & $\mathrm{Y}$ & EH_11_C & 10.39 & 0 \\
\hline 0 & 0.3 & zero & 4 & 1 & $Y$ & $\mathrm{MH}^{-1} 18 \mathrm{C}$ & 13.38 & 0 \\
\hline 0.3 & 1 & low & 15 & 1 & $\mathrm{Y}$ & MH $\mathrm{MH} \overline{\mathrm{A}} \overline{\mathrm{C}}$ & 0 & 0 \\
\hline 0.3 & 1 & low & 15 & 1 & $\mathrm{Y}$ & MH_09B_C & 0 & 0 \\
\hline 0.3 & 1 & low & 15 & 1 & $\mathrm{Y}$ & MH_11_C & 0 & 0 \\
\hline 0.3 & 1 & low & 15 & 1 & Y & _MH_18_C & 0 & 0 \\
\hline 1 & 5 & med & 24 & 1 & $Y$ & MH_03A_C & 1.9 & 2.94 \\
\hline 1 & 5 & med & 24 & 1 & $\mathrm{Y}$ & MH_09B_C & 0.62 & 2.29 \\
\hline 1 & 5 & med & 24 & 1 & $Y$ & $\mathrm{MH}^{-} 11 \overline{\mathrm{C}}$ & 3.9 & 3.78 \\
\hline 1 & 5 & med & 24 & 1 & $\mathrm{Y}$ & _MH_18_C & 7.25 & 3.92 \\
\hline 5 & 99999 & hgh & 28 & 1 & $Y$ & $\mathrm{MH} 03 \overline{\mathrm{A}} \mathrm{C}$ & 1.14 & 18.17 \\
\hline 5 & 99999 & hgh & 28 & 1 & $\mathrm{Y}$ & MH_09B_C & 0.04 & 7.21 \\
\hline 5 & 99999 & hgh & 28 & 1 & $\mathrm{Y}$ & _MH_11_C & 62.76 & 14.63 \\
\hline 5 & 99999 & hgh & 28 & 1 & $Y$ & $\mathrm{MH} 18 \mathrm{C}$ & 82.85 & 13.48 \\
\hline
\end{tabular}

Results from this table are used to create sub-catchment data in the hydrologic models. The slope categories for the impervious and pervious areas of a combined sewershed help to segregate the responses from different portions of the sewershed, thereby providing the modeler more control on these responses and achieve better and quicker hydrologic validation.

\subsubsection{Sewershed Precipitation}

A gauge-adjusted radar rainfall system was implemented in April 2000 to monitor precipitation within the Greater Pittsburgh region. The system is owned and operated by the Three Rivers Wet Weather Demonstration Program, a regional non-profit organization that made the investment to implement the system with the belief that improved precipitation estimates could significantly reduce the ultimate cost of regulatory compliance. The radar rainfall system uses a georeferenced $1 \mathrm{~km}^{2}$ pixel grid with 872 pixels required to cover the service area and 2313 pixels needed to provide coverage to the entire Allegheny county. The system is currently supported by a network of 33 heated precipitation gauges installed at an average density of $1 / 15 \mathrm{mi}^{2}\left(1 / 40 \mathrm{~km}^{2}\right)$. The radar rainfall 
system provides continuous coverage in $15 \mathrm{~min}$ time steps for storms meeting specified minimum criteria for intensity and total depth (Meeneghan et al., 2004).

For significant storms, the Doppler radar reflectivity data are related to the gauge precipitation intensity at a high degree of spatial and temporal detail to provide precise representation of precipitation through space and time during a storm event for each pixel. For smaller storms and periods of minor precipitation between significant storms, the pixel data are gauge-filled using the inverse distance weighing method. This two stage process results in a continuous time series of precipitation values for each of the 872 cells contained in the georeferenced pixel grid.

Using the inverse distance weighing method, the estimated precipitation at each grid cell is calculated as the weighted average of the precipitation of the surrounding three gauges. The weights are the reciprocals of the squares of the distances between the grid cell and the rain gauges. Summing the precipitation times, the weight of each rain gauge and dividing by the sum of the weights calculates the estimated rainfall at the grid cell. This process is shown in Figure 8.4 .

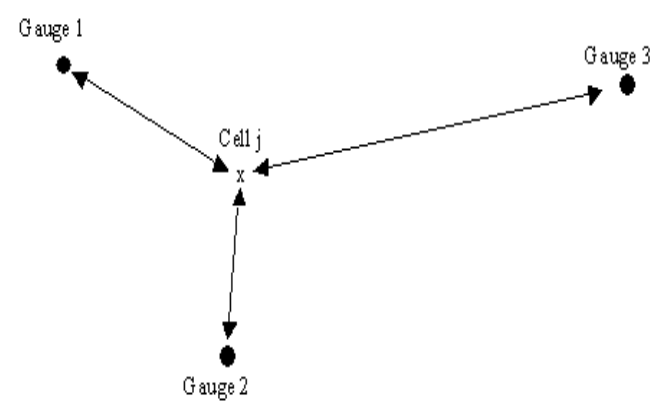

Figure 8.4 Conceptual diagram showing gauge-cell assignments.

Rainfall for cell $j$, at a particular date and time, is given by the equation:

$$
P_{j=} \sum_{i=1}^{n}\left(f_{i j} P_{i}\right)
$$

where:

$$
\begin{aligned}
P_{j}= & \text { calculated precipitation at cell number } j \\
i= & \text { rain gauge number, } \\
n= & \text { number of rain gauges assigned to the cell }(3 \text { in the } \\
& \text { example })
\end{aligned}
$$




$$
\begin{aligned}
f_{i, j}= & \text { rainfall weighting factor for rain gauge } i \text { at cell } j \text { given } \\
& \text { by: }
\end{aligned}
$$

$$
f_{i, j}=\frac{\left(D_{i, j}\right)^{-2}}{\sum_{i=1}^{n}(D i, j)^{-2}}
$$

where:

$$
\begin{gathered}
D_{i, j}=\begin{array}{c}
\text { distance between gauge } i \text { and cell } j \\
\text { (by Pythagoras's theorem), and }
\end{array} \\
P_{i}=\underset{\text { measured precipitation at rain gauge }}{i .}
\end{gathered}
$$

This continuous precipitation record is then overlaid with the GIS layer of sewershed polygons to obtain sewershed specific precipitation hyetographs. This process is shown in Figure 8.5.

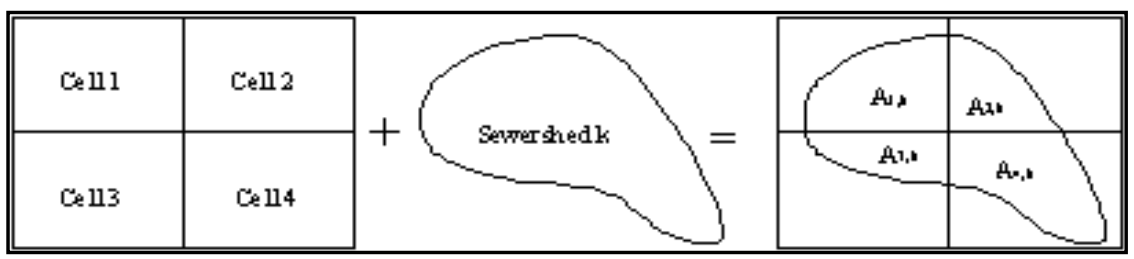

Figure 8.5 Conceptual diagram of the cell-sewershed relationship.

At a given date and time, the precipitation for a sewershed is given by the following equation:

$$
P_{k}=\sum_{j=1}^{n}\left(\frac{A_{j, k} P_{j}}{\sum_{j=1}^{n} A_{j, k}}\right)
$$

where:

$$
\begin{aligned}
P_{k}= & \text { calculated rainfall for sewershed } k, \\
j & =\text { cell number, } \\
n & =\text { number of cells contained all or partially within } \\
& \text { sewershed } k \\
A_{j, k}= & \text { area of cell } j \text { within sewershed } k, \text { and } \\
P_{j}= & \text { calculated rainfall at cell } j .
\end{aligned}
$$


The results of the calculations, consisting of rainfall at every sewershed, date, and time, are output in a SWMM readable format.

Use of the radar rainfall data to develop sewershed specific precipitation provides increased spatial and temporal accuracy in the precipitation input, thereby reducing the uncertainty in the model simulation results derived from the uncertainty inherent in the input data. The program performs the analysis described above and creates an external file with precipitation data for hundreds of sewersheds in a SWMM5 usable format.

It should be noted that even though ALCOSAN wet weather program makes use of SAS program to process the precipitation data, there is third party software available that include functionalities to process the radar rainfall data to develop sewershed precipitation.

\subsubsection{Dry Weather Flow Hydrographs}

Accurately representing the diurnal and seasonal variation in dry weather flows is an important component of an accurate model. SWMM5 allows for different methods of including the dry weather flow information in to the models. The flow monitoring data needs to be analyzed external to SWMM to characterize the dry weather flow. Large amount of quality assured flow monitoring data collected under the ALCOSAN flow monitoring program helped to accurately characterize the dry weather flow for the system. Analysis of this large amount of flow monitoring data was made possible by the use of application programs.

\section{Hydrograph Decomposition}

There are three major components of the total monitored wastewater flow. Dry weather flow is comprised of two of these components (groundwater infiltration and base wastewater flow), and the third component, rainfall dependant inflow/infiltration (RDII), represents the wet weather contribution that enters a separate sewer system during and after a rainfall event. Groundwater infiltration (GWI) represents groundwater that enters the collection system through defective pipes, pipe joints, and leaking manhole walls during dry weather. GWI may also be attributed to direct stream inflow. Base wastewater flow (BWWF) is the residential, industrial and commercial flow discharged to the sewer system for collection and treatment. GWI and BWWF together comprise the base flow, or dry weather portion of sewer flow.

Hydrograph decomposition is the process of analyzing a total monitored sewer flow hydrograph and estimating the three components of wastewater flow (RDII, BWWF and GWI). Figure 8.6 illustrates the hydrograph decompo- 
sition of monitored wastewater flow. Quality assured flow data is used to determine the average base flow (GWI and BWWF) using the Sewer Hydrograph Analysis Package (SHAPE) program. The average base flow (BWWF and GWI) time series is projected through the monitored wet weather hydrograph. The area between the wet weather hydrograph and the average base flow time series represents the RDII volume.

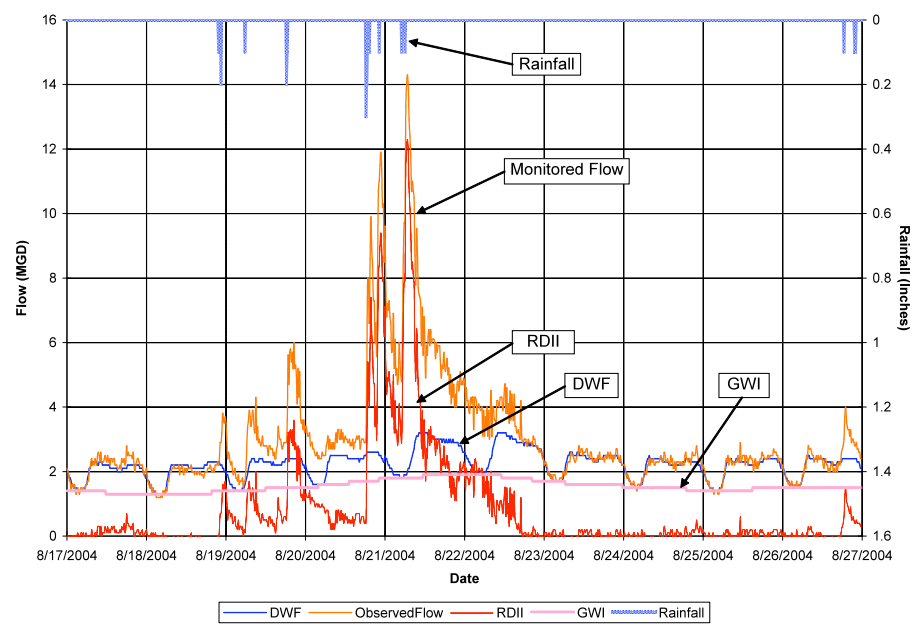

Figure 8.6 Hydrograph decomposition.

\section{Dry Weather Flows for Monitored Sewersheds}

During the monitoring period, observed weekday and weekend BWWF patterns and GWI time series are used. During the unmonitored periods average weekday and weekend BWWF patterns, and extrapolated and adjusted GWI time series derived from a downstream regional meter, are used. The BWWF pattern and GWI time series are added together to generate a continuous record of dry weather flow for a monitored sewershed.

\section{Dry Weather Flows for Unmonitored Sewersheds}

It is not feasible for all load points in the H\&H models to have corresponding flow monitoring sites. This is due to access restraints and hydraulic conditions that result in a site being infeasible for accurate and reliable monitoring (Loehlein and Meeneghan, 2007). For unmonitored sewersheds dry weather flow is derived from a downstream regional flow monitoring meter. GWI is distributed to the unmonitored upstream basins based on tributary sewered area, 
and BWWF patterns are distributed based on tributary population. In the event that monitored upstream sewersheds also exist, the monitored upstream dry weather flow time series are first subtracted from the dry weather flow time series of the downstream regional meter. Then, the resulting dry weather flow time series is distributed to the unmonitored upstream basins, again based on population for BWWF patterns and on sewered area for GWI.

The tributary population and sewered area provide readily available parameters for extrapolating dry weather flows to the unmonitored sewersheds. The estimates are reasonably adequate and representative for planning purposes and help account for weekday/weekend BWWF and seasonal variability in GWI for the unmonitored load points in the models.

\section{Continuous Record of Dry Weather Flows}

For each sewershed, the dry weather flows were computed using the process outlined in the flow chart shown in Figure 8.7 after categorizing each sewershed as:

1. Unmonitored sewershed;

2. Monitored sewershed during monitored period; and

3. Monitored sewershed during unmonitored period.

A set of post-processing programs was developed to implement the process outlined in the flowchart. For a monitored sewershed during its monitored period, both the BWWF and the GWI are derived from hydrograph decomposition analysis. For the unmonitored period, the GWI portion was extrapolated from the GWI portion of the downstream regional meter (shallow-cut monitoring site or the WWTP) and adjusted to match the dry weather flows during the monitored period. For an unmonitored sewershed, both the BWWF and GWI were extrapolated from the hydrograph decomposition results for the downstream regional meter.
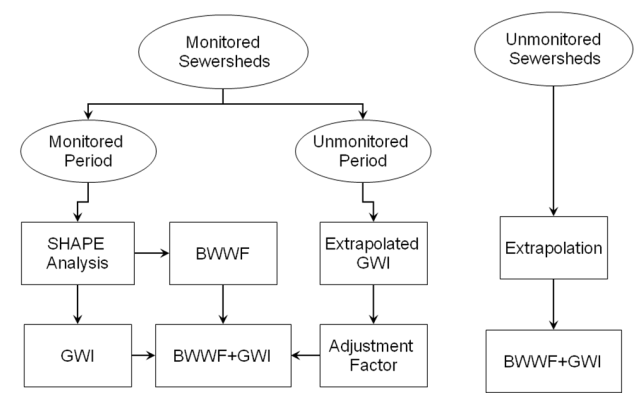

Figure 8.7 Flowchart for the generation of continuous dry weather flow time series. 
For BWWF extrapolation, BWWF of the downstream regional meter was population normalized to estimate gal/pc (per capita)/d for these sites. Extrapolated BWWF for each upstream unmonitored sewershed was computed by multiplying the population of the sewershed with the gal $/ \mathrm{pc} / \mathrm{d}$ of the downstream regional meter it contributes flows to.

For GWI extrapolation, GWI of the downstream regional meter was area normalized, to estimate gal/acre/d for these sites. Extrapolated GWI for each upstream sewershed was computed by multiplying the area of the sewershed with the gal/acre/d of the downstream regional meter site it contributes flows to.

For the monitored sewersheds a check was made to verify if the sewershed area was reasonable parameters for extrapolating GWI. The checks revealed that for some sites the extrapolated GWI based on sewershed area and using flow monitoring data from long term downstream meters was representative. But for other sites the extrapolated GWI was not representative of the GWI during monitored periods and for such sites the extrapolated GWI was adjusted based on its GWI during its monitored period to match it closely to the monitored period. The groundwater table tends to be comparatively higher during the winter and spring months. To account for this, two sets of adjustment factors were developed to adjust the extrapolated GWI for the unmonitored period for each monitored sewershed. The period between the months of November and April was considered a high GWI period, while the period between the months of May and October was considered a low GWI season. The adjustment multiplying factors for each monitored sewershed was computed as:

$$
A F=\frac{M A}{U A}
$$

where:

$$
\begin{aligned}
A F= & \text { Adjustment multiplying factor, } \\
M A= & \text { Monitored average GWI for all available data for high } \\
& \text { or low season, and } \\
U A= & \text { Unmonitored average GWI for all available data for } \\
& \text { high or low season. }
\end{aligned}
$$

For each monitored and unmonitored sewershed, time series were developed or extrapolated for the BWWF and GWI components. They were then added together to generate a continuous dry weather flow time series. Figure 8.8 shows the continuous dry weather flow record for a monitored sewershed for which the extrapolated GWI based solely on the area of the sewershed was found to be under-estimated and required the use of adjustment factors. The plot shows dry weather flow time series during the monitored period (TS1), the extrapolated dry weather flow time series for the sewershed before adjustment 
(TS2) and the dry weather flow time series after adjustment (TS3). The time series TS3 is the final dry weather flow (inflow) for the sewershed. During the monitored period, the inflow is equal to the dry weather flow derived from the hydrograph decomposition analysis of the observed data (TS3 time series is under TS1 time series).

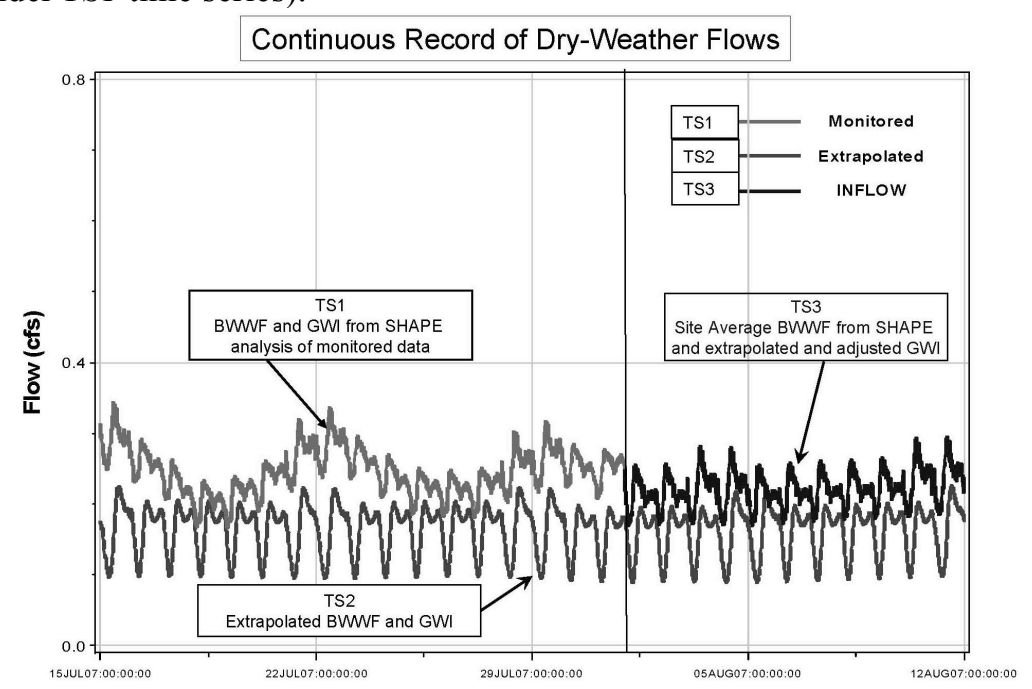

Figure 8.8 Continuous dry weather flow record for a monitored sewershed.

\subsection{Post-Processing Programs}

\subsubsection{Hydrologic Validation Plots}

The accuracy of the developed model during wet weather events is essential when recommending appropriate wet weather control facilities. To make sure that the model accurately represents the best available information, a rigorous program of wet weather validation was applied to the ALCOSAN models using quality assured flow monitoring data.

Hydrologic validation was conducted for all of the monitored combined sites to properly simulate the wet weather response from the monitored sewersheds. Hydrologic validation of a monitored sewershed was an event based exercise, where the validation of a given monitoring site was based on the maximum number of successfully monitored wet weather events. The number 
of events used for validation depended on the type of the monitoring site and the period for which the site was monitored.

Using time series plots, graphical comparisons were made of peak flow and volume for each wet weather event occurring during the validation period. Statistical comparison plots were developed to illustrate the goodness-of-fit between the modeled response and the monitored data.

For a large number of storm events, the simulated storm volumes and peak flows versus the corresponding monitored volumes and peak flows were plotted. For each of the monitored storm events, the model-simulated peaks and volumes were compared with the monitored storm peaks and volumes.

Regression plots were also generated to make statistical comparisons of the simulated flows and the monitored flows. The regression plots present the goodness of fit for the event volumes and event peaks. For a perfect fit, the trend line drawn through the data points should have a slope of 1.0 and an intercept of 0.0 . Storm events with missing, incomplete or errant flow monitoring data, unreasonable responses in either the simulated flows or monitored flows or inaccurate or unreasonable precipitation data were identified and deemed outliers. These outlier storm events were assigned a weight of zero for the regression analysis, so they did not affect the results of the regression analysis.

The outlier events were not included in the regression analysis because it would create a bias in the regression plots. The iterative process of optimizing the runoff and RDII parameters was continued until the following validation objectives were achieved:

1. On the statistical regression plots, a regression line with slope close to 1 indicates that the modeled storm event volumes and peak flow rates are consistent with the monitored volumes and peak flow rates;

2. On the statistical regression plots, an intercept of the regression line close to 0 indicates that the modeled event volumes and peak flow rates were not biased (i.e. consistently oversimulating or under-simulating) with respect to the monitored volumes and peak flow rates;

3. On the statistical regression plots, an R-square value of the regression line close to 1 indicates that the degree of scatter in the data points in the regression plot is low; and

4. On the time series plots, matching as closely as possible the ratio of the time to peak, shape and magnitude for the monitored and simulated events.

Hydrologic model validation is an iterative process which requires multiple model simulations and the post-processing of the simulation results to evaluate 
the progressive improvement of the overall model validation. Post-processing of model simulation results includes generating regression plots to make statistical comparisons of simulated and monitored flows and generating time series plots for the simulated and monitored hydrographs for all the analyzed storm events.

The use of SAS programs to facilitate the post-processing of the model simulation results make the process more efficient and less labor intensive. The SAS program makes use of the following pieces of information to generate the volume and peak flow regression plots and the event time series plots:

1. Event definition file, which lists the event number, start date and time, end date and time, and the weight assigned to the event ( 1 for kept event and 0 for outliers);

2. Monitored flow hydrograph and representative precipitation time series; and

3. Simulated flow hydrograph.

Illustrative examples of the volume and peak regression plots and a time series plot showing the monitored and simulated flows can be found in Figures 8.9, 8.10 and 8.11 respectively. In Figures 8.9 and 8.10, the filled circles represent the kept events while the open circles represent the outlier events.

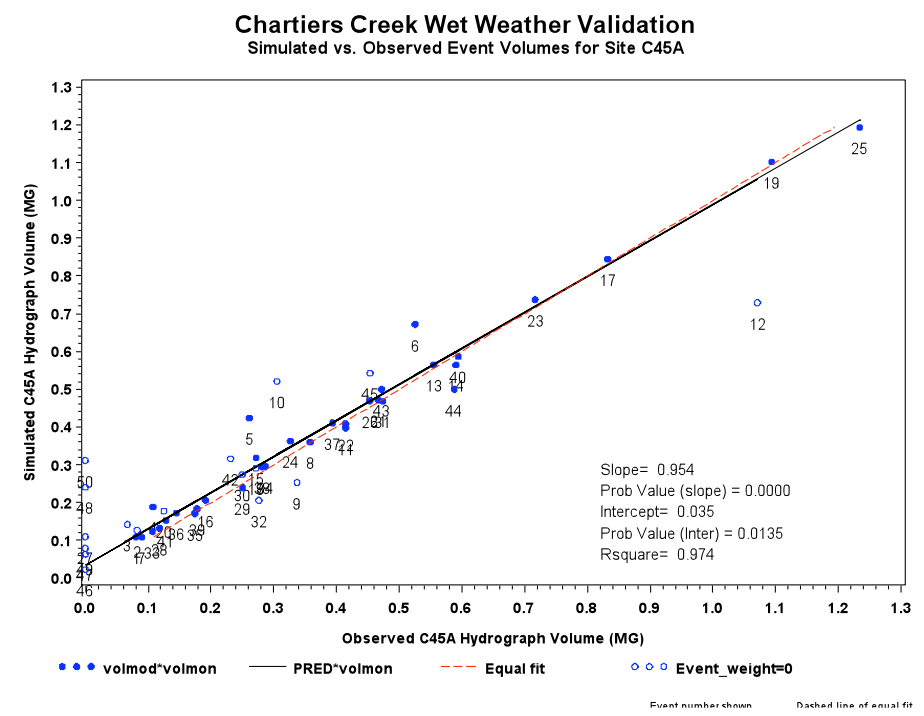

Figure 8.9 Regression plot for event volumes. 


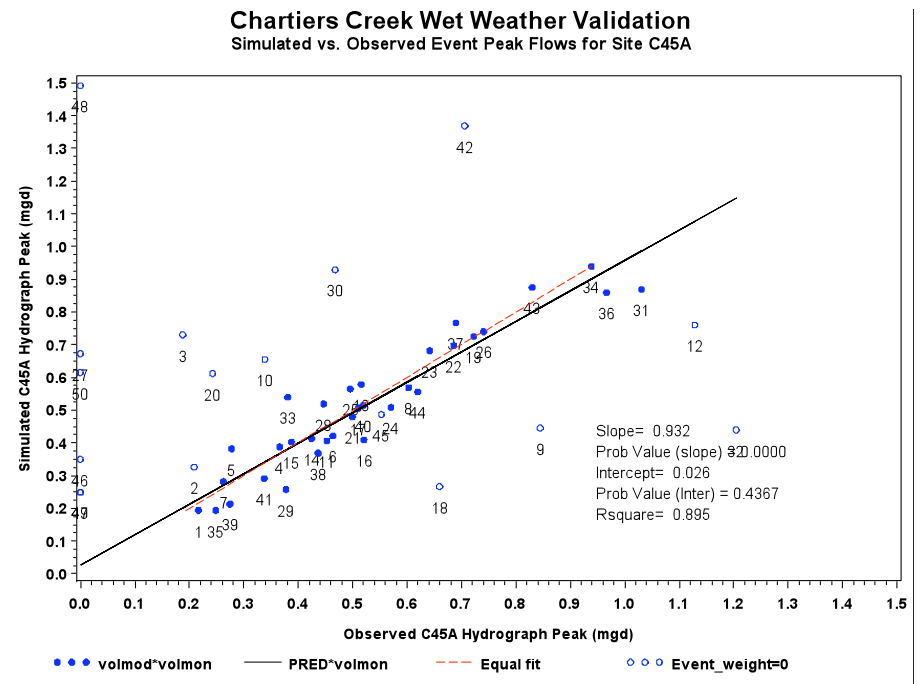

Figure 8.10 Regression plot for event peak flows.

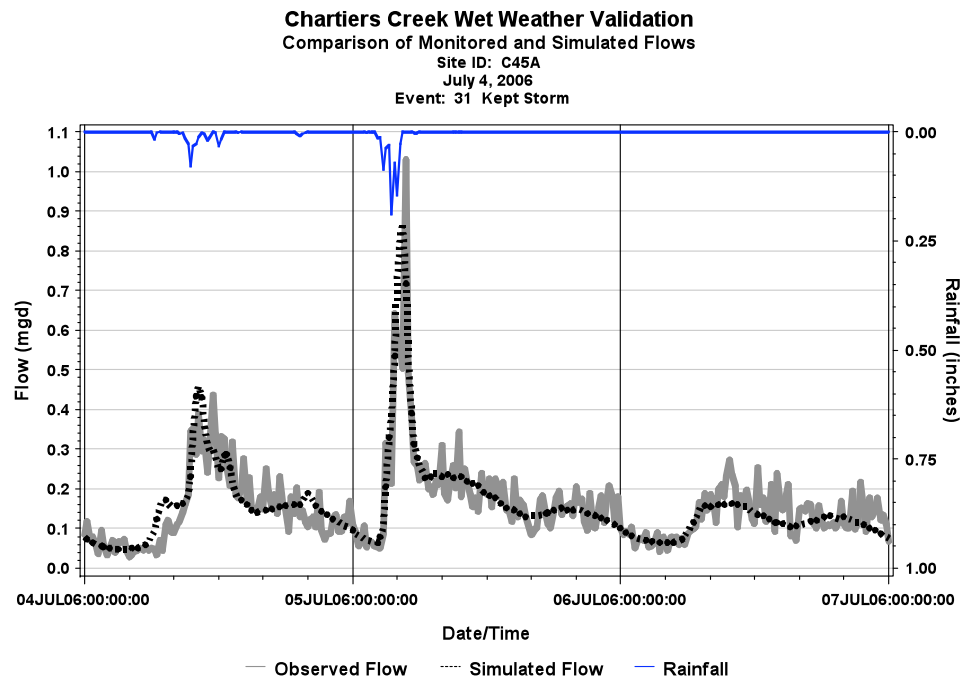

Figure 8.11 Simulated and monitored flow time series comparison. 
The advantage with using the SAS programs for hydrologic validation is that it allows the validation to be an event based exercise. The user has the ability to identify the outlier events with missing data or uncharacteristic system responses, including which could induce a bias in the validation results. Use of the SAS programs also allows the user to choose if the dry weather flows are considered or excluded during the hydrologic validation process. Using the SAS programs the user can develop validation plots and evaluate the validation progress for multiple sites after a model simulations with a single run of the programs, which makes the process very efficient.

\subsubsection{Plots for Model Simulation Results Quality Assurance}

After ensuring the quality of the input datasets used for model simulation, it is also important that the model simulation results be thoroughly quality assured. The summary tables included in the SWMM5 report files provide vital information to judge a model simulation. Plotting the simulated results at critical locations in the model is a simple and efficient way of evaluating the details of a model simulation. For smaller models with limited number of hydrologic and hydraulic elements, the output files generated for a model simulation are also small. For these cases the SWMM5 GUI can plot the results like simulated flows in conduits and head and depth at junctions rather quickly, which can then be reviewed to evaluate the model performance. As the model size increases so do the model simulation output files sizes. With the data reported for huge number of hydrologic and hydraulic elements, SWMM5 GUI takes significant amount of time retrieving and then plotting the simulation results. To quickly screen the model simulation results at critical locations in a model and identify potential problems that may require further investigation, postprocessing SAS programs were developed. The flow time series plots at the regulator structure help quickly screen the performance of the model at the regulator structure and identify any model instability issues.

These programs generate a variety of plots making use of the information reported and saved in the report file for specific nodes and conduits. The types of plots generated to facilitate the review process include:

1. Plots comparing the simulated and monitored HGL time series at various locations along the deep tunnel interceptor system;

2. Plots comparing the simulated and monitored flows and depths along various locations along the shallow-cut interceptor system; and 
3. Plots showing the influent flow, regulated flow and overflow time series at all the regulator structures.

Illustrative examples of these plots can be found in Figures 8.12, 8.13 and 8.14 .

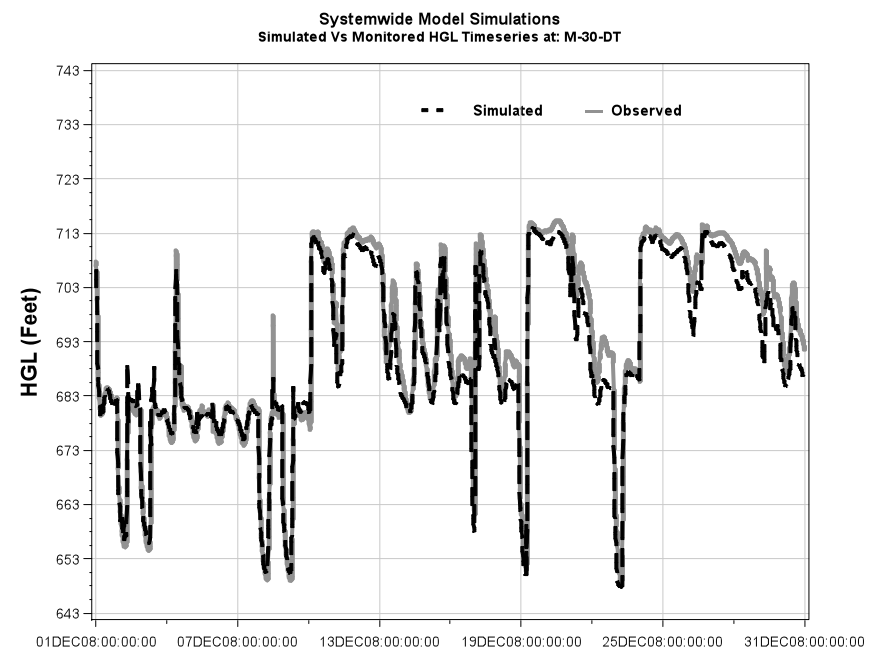

Figure 8.12 Simulated and monitored HGL along the deep tunnel interceptor.

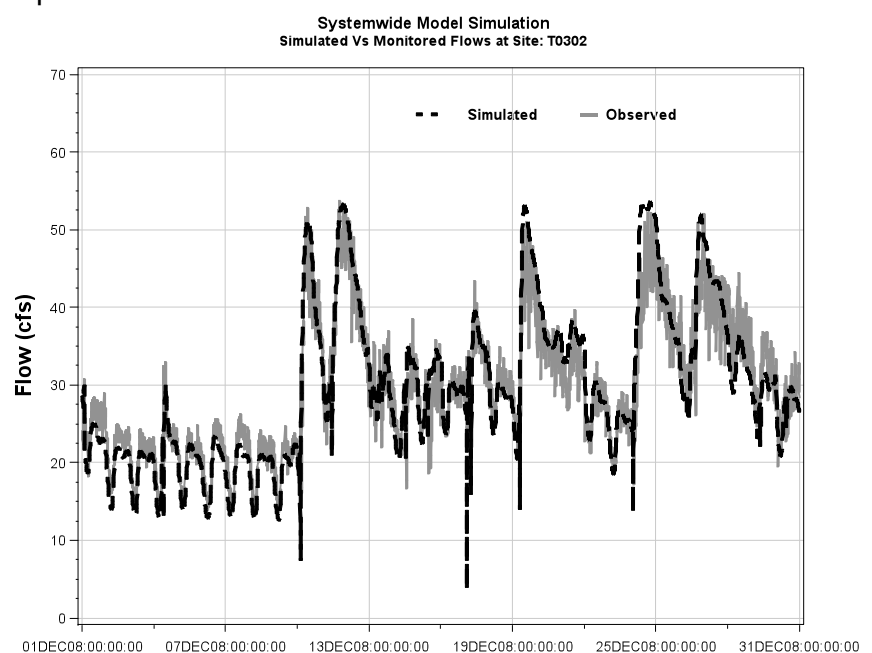

Figure 8.13 Simulated and monitored flows along a shallow-cut interceptor. 


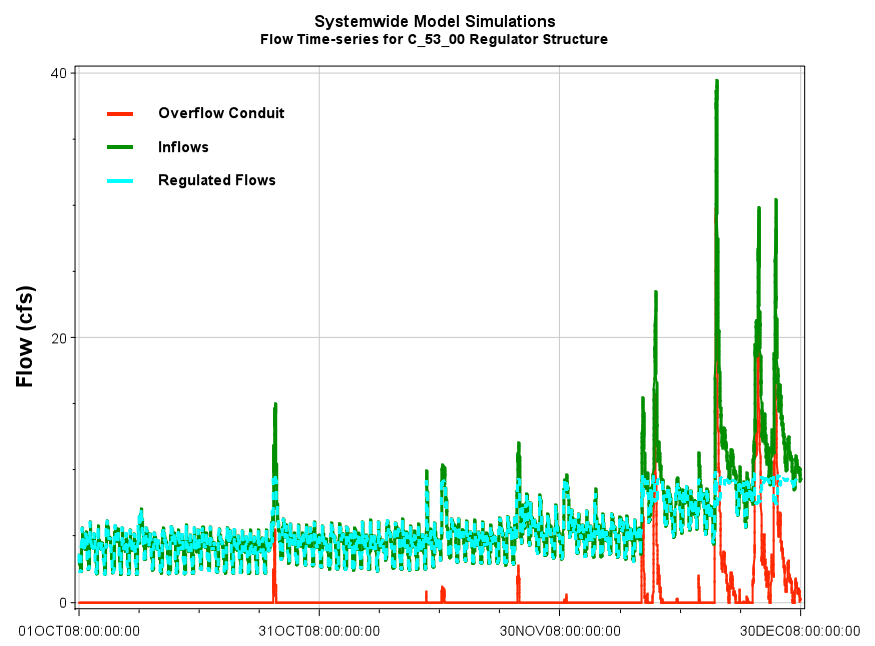

Figure 8.14 Flow time series at a regulator structure.

\subsubsection{Overflow Discharge Hydrograph Plots and Statistics}

One of the most common applications of a CSO model is the simulation of overflow discharge hydrographs at designated locations in the collection system. Usually these discharge points are located at regulator structures (also called a diversion structures). The purpose of a regulator structure is to intercept and convey all of the dry weather flow, and a regulated fraction of wet weather flow, to the wastewater treatment plant. The diverted dry weather and wet weather flow is conveyed by a connector pipe to the interceptor, while wet weather flows in excess of the design capacity of the regulator are diverted to a receiving stream.

The statistics functionality included in the SWMM5 GUI can calculate the overflow discharge statistics at a given outfall. Based on the inter-event time specified by the user it can calculate the overflow frequency (the number of overflow discharge occurrences) during the simulation, and also the overflow discharge volume and duration of each occurrence. The procedure of selecting outfalls and calculating the overflow statistics using the SWMM5 GUI and exporting them into a spreadsheet or text editor for post-processing makes sense if there are limited number of outfalls in a model, or if the process needs to be carried out for some of the outfalls in a large model. But this process becomes increasing cumbersome and time and labor intensive if it needs to be repeated for a significant number of outfalls in a large model. 
To automate the process of calculating the overflow statistics of frequency, volume and duration, a post-processing program was developed. The program processes the overflow hydrographs at the outfalls in the system that SWMM5 saves in the outflows interface file. Alternatively the overflow hydrographs in the overflow conduits can be reported and saved in the report file. The user specifies the inter-event time for the calculation of the overflow discharge frequency. The program generates several overflow statistics summary tables. The overall summary table for the complete model lists all the outfalls in the model, and their corresponding overflow discharge frequency, volume and duration. The listed volume and duration is the sum total for all the overflow discharge occurrences at a incumbent outfall during the simulation period. Table 8.2 shows an illustrative example of this overall summary table.

Table 8.2 Overall overflow statistics summary for the system outfalls during a simulation period.

\begin{tabular}{||c|c|c|c||}
\hline \hline Outfall & Frequency & Total Volume(MG) & Total Duration(Hrs) \\
\hline \hline X750F & 10 & 2.288 & 49 \\
\hline X760F & 5 & 0.727 & 11 \\
\hline X77OF & 3 & 0.263 & 9.75 \\
\hline X780F & 5 & 2.776 & 51.25 \\
\hline X5310OF & 5 & 6.599 & 46 \\
\hline X530F & 9 & 33.613 & 292.5 \\
\hline X5406OF & 0 & 0 & 0 \\
\hline X54OF & 5 & 2.7 & 50 \\
\hline X5502OF & 4 & 3.092 & 67.75 \\
\hline X550F & 0 & 0 & 0 \\
\hline
\end{tabular}

Summary tables are also generated for individual outfalls. These summary tables list the overflow discharge occurrence, the start time of the occurrence, the volume and the duration. The count of the overflow discharge occurrences corresponds to the frequency for that outfall in the overall summary table. Table 8.3 shows an illustrative example for an individual outfall summary table.

Table 8.3 Overflow statistics summary for an individual site.

\begin{tabular}{||l|c|c|c|c||}
\hline \hline Link & Event & Event Starttime & Event Volume(MG) & Event OF duration(Hrs) \\
\hline \hline X53OF & 1 & 25OCT08:05:30:00 & 0.663 & 8.75 \\
X53OF & 2 & 13NOV08:08:30:00 & 0.008 & 0.5 \\
\hline X53OF & 3 & 15NOV08:06:00:00 & 0.137 & 7.5 \\
\hline X53OF & 4 & 24NOV08:16:00:00 & 0.311 & 7 \\
\hline X53OF & 5 & 30NOV08:13:00:00 & 0.011 & 1.5 \\
\hline X53OF & 6 & 10DEC08:04:30:00 & 4.391 & 41.25 \\
\hline X53OF & 7 & 14DEC08:14:30:00 & 0.007 & 1.25 \\
\hline X53OF & 8 & 17DEC08:07:00:00 & 0.108 & 3.75 \\
X53OF & 9 & 19DEC08:07:30:00 & 27.975 & 221 \\
\hline
\end{tabular}

In addition to the summary tables, the program also generates plots showing the overflow discharge time series. These plots can be used to screen for model 
simulation issues like dry weather overflows or unusual overflow discharge occurrences at some regulator structures. Figure 8.15 shows an illustrative example of the overflow discharge time series plot.

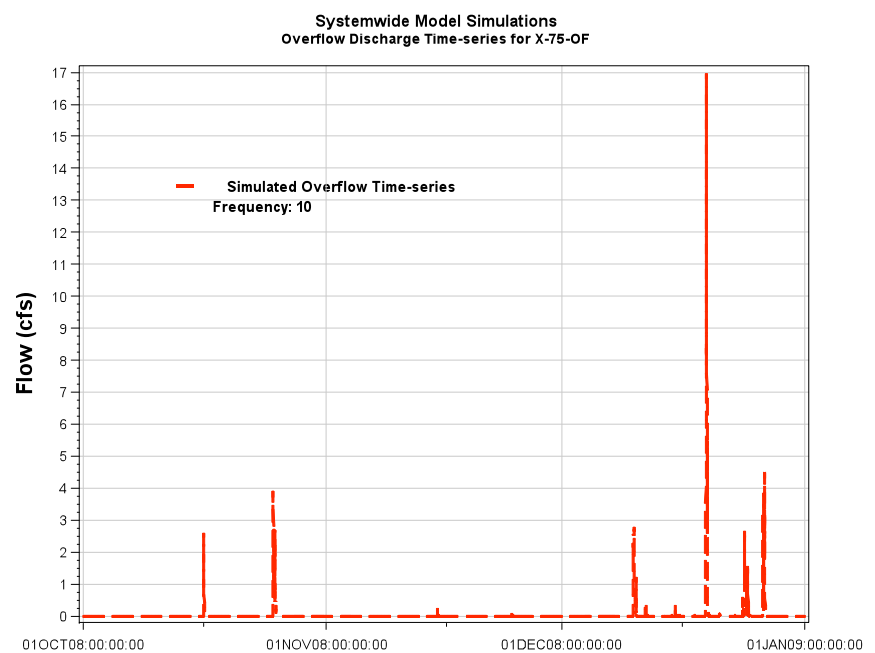

Figure 8.15 Overflow discharge hydrograph at a regulator structure.

\subsection{Conclusions}

For smaller models, with limited number of hydraulic and hydrologic elements and small input datasets that generate small output files, SWMM5 GUI and some available third party software provide ample functionality and are able to efficiently manage the input datasets and analyze and process the output files. But as the size of the model, their related input datasets and generate output file sizes increase, customized solutions outside the framework of SWMM are needed to effectively manage the input datasets and analyze and process the output files. The programs described in this chapter were developed to achieve this objective.

As new and updated GIS, precipitation and flow monitoring data becomes available, use of these programs would facilitate regular and quick refinement of the models and the input datasets. During the evaluation and optimization of regional control alternatives in support of the development of the wet weather plan, use of the post-processing programs will facilitate quick evaluation of the results from a significantly large number of model simulations. 
In addition to efficiency, such customized programs also help implement the unique requirements of the projects. Use of such programs substantiates the performance and broadens the applicability of SWMM.

\section{References}

Khan, K. and T. Meeneghan. 2006. "Developing a Planning-Level System-Wide Model using SWMM." Journal of Water Management Modeling R227-03. doi: 10.14796/JWMM.R227-03.

Loehlein, M. and T. Meeneghan. 2007. "Extrapolation of Available Monitoring Data to Facilitate Long-Term Continuous Simulation Modeling." Journal of Water Management Modeling R228-12. doi: 10.14796/JWMM.R228-12.

Meeneghan, T., T. Prevost and K. Khan. 2004. "Impacts of Rainfall Data on Model Refinement in Greater Pittsburgh." Journal of Water Management Modeling R223-18. doi: 10.14796/JWMM.R223-18. 